\title{
50 \\ Transport Investment Appraisal and the Environment
}

\author{
Peter Nijkamp* \\ Barry Ubbels \\ Erik Verhoef:
}

Department of Spatial Economics, Faculty of Economics and Business Administration, Vrije Universiteit Amsterdam

* Tinbergen Institute 
Tinbergen Institute

The Tinbergen Institute is the institute for economic research of the Erasmus Universiteit Rotterdam, Universiteit van Amsterdam and

Vrije Universiteit Amsterdam.

Tinbergen I nstitute Amsterdam

Keizersgracht 482

1017 EG Amsterdam

The Netherlands

Tel.: +31.(0)20.5513500

Fax: $\quad+31 .(0) 20.5513555$

Tinbergen Institute Rotterdam

Burg. Oudlaan 50

3062 PA Rotterdam

The Netherlands

Tel.: $\quad+31 .(0) 10.4088900$

Fax: $\quad+31 .(0) 10.4089031$

Most TI discussion papers can be downloaded at

http://www.tinbergen.nl 


\title{
TRANSPORT INVESTMENT APPRAISAL AND THE ENVIRONMENT
}

\author{
Peter Nijkamp \\ Barry Ubbels \\ Erik Verhoef \\ Free University Amsterdam \\ Department of Spatial Economics \\ De Boelelaan 1105 \\ $1081 \mathrm{HV}$ Amsterdam
}

Key words: transport, cost-benefit analysis, environment

JEL codes: R42, D61, Q20

\begin{abstract}
This review considers the role of environmental effects in transport investment appraisal, mainly from the perspective of cost-benefit analysis, the most widely adopted appraisal technique. Although the basic principles of CBA are straightforward, several complications are identified that may play an important role in practical CBA's. These include second-best aspects, difficulties with discounting and with the spatial scope of CBA's, and the relation between CBA and the popular but multi-faceted and often ill-defined policy concept of sustainable development.
\end{abstract}




\title{
TRANSPORT INVESTMENT APPRAISAL AND THE ENVIRONMENT
}

\author{
Peter Nijkamp \\ Barry Ubbels \\ Erik Verhoef \\ Free University Amsterdam \\ Department of Spatial Economics \\ De Boelelaan 1105 \\ 1081 HV Amsterdam
}

\section{Introduction}

Investment appraisal is an important issue in transport planning and policy. The investments are usually long lasted, practically irreversible, and costly, and may at the same time have a great impact on people's lives and the development of communities and regions. Investment decisions should therefore be well thought through, and various alternatives should be compared carefully before making a final choice. The most widely applied appraisal technique in transport is cost-benefit analysis (CBA). CBA essentially compares the projected future stream of benefits from a project with its initial and future costs. It thus allows a ranking of several competing projects or project variants, or a decision not to undertake any of these. Investment decisions on transport investment are usually made by public authorities, often motivated by infrastructure's (sometimes merely perceived) 'public good' character'. Besides, uncertainty in future patronage and relatively high fixed costs make private parties only rarely interested in investing in transport infrastructure. Consequently, the central criterion employed in practical transport investment appraisal is often related to the project's contribution to social welfare - often operationalized as social surplus - rather than the more narrow criterion of profits that a private enterprise would use.

The evaluation of projects is not straightforward. It should identify key consequences of a proposed project and provide quantitative information about them. The various types of effects should next be made comparable, so that a choice can be made in the typical case where different project alternatives would score better on different criteria, and no strictly dominant alternative is available. In CBA, the aim is to accomplish this by expressing the effects in the same units (money, for cost benefit analysis), so that tradeoffs between different types of effects can be made. Transport investments are however characterised by a wide variety of effects, most of them long-lasting and sometimes hard to quantify in terms of monetary equivalents. One specific type of effect, which is difficult to measure, is central in this contribution: environmental effects. The construction and subsequent use of infrastructure will have important external effects (such as noise pollution and emissions), that have to be included in a social evaluation as they affect the welfare of society. This contribution will discuss some key issues that will play a role in transport investment appraisal when environmental externalities ${ }^{2}$ are present. 


\section{Transport infrastructure investment and appraisal methods}

The main principle of economic investment appraisal is straightforward. A profit maximizing firm should, in the absence of budget constraints, undertake investments when the projected financial 'net present value' - the present value of a discounted stream ${ }^{3}$ of current and future net revenues - is positive. For public investments, the main difference would be that instead of profit maximization, social welfare maximization should be the main objective steering investment decisions. While there are many complexities in undertaking commercial investment appraisal (e.g., allowing for risk of unexpected changes in demand), public investment appraisal has attracted most attention in the transport literature. The wide ranging and long-term effects of most major changes in transport infrastructure necessitate the employment of sophisticated methods of project appraisal and of comprehensive techniques for decision-making. For example, the range of effects that have to be taken into account with the investment of a road is wide (see Table 1).

\begin{tabular}{ccc}
\hline $\begin{array}{c}\text { Traffic economy and } \\
\text { road maintenance }\end{array}$ & $\begin{array}{c}\text { Environmental and } \\
\text { land-use effects }\end{array}$ & Regional development \\
\hline Traffic safety & Noise & $\begin{array}{c}\text { Regional economic growth, } \\
\text { employment, and trade balance } \\
\text { Travel time }\end{array}$ \\
Comfort & Air pollution & Effects for trade, industry and \\
Vehicle costs & Barrier effects & tourism \\
Maintenance & Water pollution & \\
User benefits & Vibrations & \\
& Landscape/scenery & \\
& Nature conservation & \\
& Land development & \\
\hline
\end{tabular}

Adapted from: Button (1993b)

Table 1. Some main effects resulting from the construction of a road

This wide range of effects may make it very difficult for policy makers to decide whether a project is worthwhile to undertake, or to rank competing projects. A skilfully performed project appraisal will then be helpful in structuring information. The rise in the development of appraisal techniques for transport projects came in the late 1960s and early 1970s (Grant-Muller et al., 2001). Key topics of research in those days included the measurement of the relevant monetary values for time and safety benefits. This work found its application in the appraisal of individual large projects, in the development of standard appraisal methods for smaller projects such as new sections of road, and in the assessment of city and regional transport plans.

$\mathrm{CBA}$ is the common basis for most appraisal frameworks. It aims at expressing all relevant effects of a particular project in a common numéraire, namely in monetary terms - hence costs and benefits. Despite its appeal, several limitations exist and are well recognized. Two major weaknesses often mentioned include the unavailability of accurate estimates of (unit) shadow prices for various effects, and the method's (often implicit) assumption that different types of effects can be regarded as 'additive substitutes', meaning that these effects can be traded off on a dollar-by-dollar basis. As a consequence, several complementary approaches have been deployed, such as cost-effectiveness analysis, planning balance sheet methods and shadow project approaches. An alternative approach may be objectives led, with the goal of maximising with respect to a set of socially based objectives rather than market values. 
Multicriteria analysis (MCA) typifies this approach. MCA is often seen as competing with CBA, although there is no fundamental reason why the two approaches may not be used in an entirely complementary manner within an overall framework (Grant-Muller et al., 2001). It has been argued that that the efficiency check on transport decisions can most properly be carried out by means of CBA methods, while equity and sustainability checks need broader approaches, based on MCA approaches (SAMI, 2000). For an overview of MCA in the context of environmental evaluation, we refer to Janssen and Munda (1999). Nijkamp and Vreeker (2003) consider MCA in environmental evaluation for transport.

Transport has proved a fruitful area for the application of CBA techniques. Most European national frameworks now have a CBA at the core (Grant-Muller et al., 2001). Therefore we will say more about cost-benefit analysis below, and will consider the role of environmental effects in transport investment appraisal mainly from the perspective of CBA.

\section{Cost-benefit analysis in transport: some issues relevant for environmental appraisal}

The basic philosophy of CBA can be traced back to the writings of Dupuit (1844). It is essentially not a purely accounting system, but an evaluation method based on applied welfare theory. It seeks to determine the net social surplus of public investments or of institutional decisions. Prest and Turvey (1965) defined CBA as a practical way of assessing the desirability of projects for which it is important to take a long view (looking at repercussions in the future) and a wide view (allowing for side effects of many kinds). Since the function of public investment is to advance social welfare, CBA is employed in public investment decisions where market imperfections require that a wider viewpoint is adopted than that of the private profit maximising investor. This makes CBA very useful to appraise transport investments, where the public government is most often the investor. Transport was therefore amongst the first fields in which CBA came into regular application. For instance, in Britain two of the classical seminal applications of the technique were the studies of the M1 motorway and of the Victoria Line - an underground railway line in London (Nash, 1993). Following these studies, techniques were developed for the routine appraisal of road schemes and of public transport schemes where these have a social intent.

Many detailed reviews on CBA in transport are available, including Nash (1993), Small (1999), Mackie and Nellthorp (2001), and Grant-Muller et al. (2001); and Hanley (1999) considers CBA from the perspective of environmental policy and management. It is certainly not our purpose to redo the work in these reviews here, and to provide another overview of the essentials of CBA in transport investment appraisal. Very briefly, the major steps would include, after the determination of a sufficiently broad set of project alternatives to be considered, for every project (alternative): (1) an assessment and quantification of all the alternative's relevant effects - relative to some well-defined 'base' scenario - in current and future periods; (2) the expression of these effects in monetary terms; (3) the discounting of these costs and benefits to make them comparable to costs and benefits in the current period; (4) so that eventually the project's net present value (NPV) can be determined. Instead, we will focus on a few aspects of CBA in transport that are particularly relevant also for the appraisal of environmental effects.

\subsection{Welfare measurement in applied CBA's: social surplus}

CBA typically uses consumer surplus (CS) as the operational measure for benefits. This measure has some well-recognized theoretical properties that make it less attractive than Hicksian welfare measures such as compensating and equivalent compensation (CV and EV; see Varian, 1992) from a theoretical perspective. 
In particular, $\mathrm{CS}$ is not an exact monetary measure for welfare changes, and need not be uniquely defined if multiple prices or quantities change simultaneously. However, these drawbacks are often taken for granted, as a countervailing immediate advantage of CS is that it is based on more or less directly observable market demand functions by taking individuals' willingness to pay as the basis for the determination of benefits. Moreover, Willig (1976) has argued rather convincingly that the discrepancy between CS and the theoretically more correct measures of CV or EV need not be large in applied work, and may often be negligible when compared to other uncertainties inherently present in practical appraisals - especially when income effects due to the projects considered are relatively small. The costs are, when appropriate, measured in market prices. If social values however differ from market prices when the latter do not properly reflect marginal social costs (one instance would be wages under high involuntary unemployment, another concerns environmental pollution for which no market price generally exists), so-called shadow prices are used instead to calculate the social costs involved in the project. Section 4.2 below will discuss a number of techniques that have been used for determining shadow prices of pollution and environmental quality, and will explain that consistent with the CBA methodology, also these typically seek to assess society's willingness to pay to prevent pollution.

\subsection{CBA under various 'second-best' conditions}

If transport investments would take the form of continuous rather than discrete expansions, and if the transport system and the spatial economic system it 'serves' would operate under first-best conditions (with all prices reflecting marginal social costs), CBA would be relatively straightforward - at least if the prediction of effects were not too difficult and reliable shadow prices for each of these were available. However, the discreteness of most projects prevents marginal analyses from being appropriate. One implication is that induced demand effects must be taken into good consideration, at the risk of obtaining seriously biased results otherwise (Williams and Moore, 1990; Small, 1992). And second-best conditions prevailing (with non-optimal prices in transport or related markets) will typically mean that induced indirect effects from the investment - be it elsewhere in the network, in other transport modes, or in economic sectors other than transport - may imply substantial (indirect) welfare effects that ought to be accounted for in CBA.

For instance, an important feature of transport that often complicates applied welfare analyses is that it usually manifests itself on a network. As a result, the benefits and costs associated with the addition of a link (e.g., a road) to an existing network, or the expansion of its capacity under conditions of congestion, will typically not be confined to that link itself. Instead, re-routing, rescheduling, and other behavioural responses will generally occur after an investment, until a new network equilibrium is reached. This means that costs and benefits may change for links and origin-destination pairs throughout the network, and will not be confined to the link where the investment takes place. Especially when the use of the network at these other links is not optimized from the social perspective through optimal pricing (i.e., when secondbest conditions apply), these induced changes may constitute substantial welfare effects, that ought to be taken into account in a comprehensive CBA.

In applied work, the network-wide welfare effects of an improvement of a single link of that network are often approximated using the so-called rule of half, which would be a precise measure for surplus changes only if all demand and cross-demand functions would be linear (Button, 1993b). This rule estimates the total welfare of an improvement as the sum (over all user groups) of the average use level for 
a group (averaged over the situation without and with the project carried out), multiplied by the change in average (per user in that group) generalized costs (see, for instance, Mackie and Nellthorp, 2001). These generalized costs include all costs experienced by a user of the network, typically encompassing both monetized (e.g. fuel) and non-monetized (e.g. the valuation of travel time) components. The importance of considering such network effects in CBA is illustrated dramatically by the famous 'Braess paradox' (Braess, 1968), according to which the addition of a link to a congested network on which no optimal congestion prices are set, can actually increase total travel costs.

Network effects are also important to consider when estimating the environmental impacts of an improvement in a single link. Even when only total emissions, over the entire network, would be relevant for determining the environmental costs, as would for instance seem appropriate for the emission of greenhouse gases, it is important to correct the measured change in emissions on the link itself for induced changes elsewhere on the network. These changes can involve both decreases (for instance for parallel links) and increases (for instance for serial links, when expanded capacity generates additional traffic). Calculating these changes requires predicting the new network equilibrium that will arise once the project investigated is completed. Whether induced increases or decreases in traffic elsewhere in the network will lead to additional welfare gains or welfare losses will depend on whether those links are initially underpriced or overpriced. Contrary to popular beliefs, overpricing need not be exceptional in (road) transport, given prevailing rates of gasoline taxes; especially not in off-peak travel (e.g., Parry and Bento, 2002 (Table 1)). In such cases, induced increases in traffic may lead to net welfare increases, despite the induced increase in emissions.

Things may become further complicated when the marginal environmental costs associated with a given unit of emissions vary over time or place (e.g., over links). For instance, when seen from the environmental perspective, the expansion of a ring-road around a city may induce negative environmental effects due to the generation of additional traffic or perhaps due to the increase average trip lengths, but may generate positive environmental effects to the extent it succeeds in attracting traffic previously using the inner-city network, where marginal external environmental costs may be significantly higher due to the greater population density, the closer proximity of recipients of the emissions, or because 'stop-and-go' inner-city traffic will typically cause higher emissions per vehicle-kilometre. Likewise, an expansion of capacity may lead to the occurrence of the so-called 'return-to-the-peak' phenomenon. In addition to the implied direct benefits (people travel closer to the preferred time) and costs (congestion will not reduce by as much as it would without a return-to-the-peak), this may again affect the marginal environmental external costs of a given user, and thus affect the project's environmental costs. A positive indirect environmental effect of a return to the peak (compared to the situation where people would not adjust their behaviour following the capacity expansion) would occur if these marginal costs are lower in the peak than outside it, as may be the case for noise annoyance: an extra car will have a very limited impact on total traffic noise in peak travelling, but may be a distinct nuisance outside the peak. A negative indirect effect occurs in the reverse situation, for instance when the emissions per vehicle mile are higher in stop-and-go peak travel, or at low average speeds in general, than for freely flowing traffic.

These examples show that, just as is the case for the determination of total user benefits and costs following the improvement of one link in a network, it is also for the determination of environmental (and noise) costs important to consider the (dynamic) network equilibrium effects of the proposed change for a comprehensive cost-benefit analysis. The effects occurring elsewhere than on the link itself may be 
substantial, and may thus strongly affect a given project's overall cost-benefit ratio, as well as the ranking (in welfare terms) of competing projects.

Although we have phrased the above discussion in terms of a uni-modal network, the same type of arguments would of course apply when taking a multi-modal perspective. Put simply: the extra emissions resulting from an additional passenger on a new public transport service would have to be corrected for the emissions this person may have caused prior to the investment, be it smaller (when he cycled) or larger (when he drove a car) than in the new situation, for a comprehensive assessment. The implied welfare effects will typically be larger in absolute terms when prices on these other modes deviate more strongly from optimal ones.

A second type of complexity in the environmental appraisal of transport infrastructure investments is closely related to the question of whether or not 'indirect economic effects' of such investments would exist, that should be added to the 'direct effects' as can be identified based on the surplus as measured by the demand function for transport. In defending the case of such indirect effects, often appeal is made to the increased economic activity that may follow a successful infrastructural expansion, and for which it is believed that the associated net benefits, because they arise primarily in a market different from the transportation market, would not be captured in an analysis that derives benefits only as pertaining to the demand for transport. However, a closer examination of these arguments often reveals that these benefits in fact are reflected properly by the demand function for transport after all. The emerging view is that only when market failures exist in the markets 'served' by the infrastructure considered, there would be net welfare effects of transport infrastructure investments that are not properly reflected by the demand function for transport (Small, 1999; SACTRA, 1999). Examples of such market imperfections include market power (that can be reduced by exposing spatial monopolists to greater competition through greater accessibility) and agglomeration externalities (unpriced benefits of clustering in space, that can be exploited to a greater degree when infrastructure investments allow a further growth of an agglomeration). However, it should be emphasized that the implied indirect effects are by no means by definition positive (SACTRA, 1999).

One example of a negative indirect effect that should be accounted for in a transport CBA concerns the case where the investment would lead to a production expansion of a polluting industry, that is not currently taxed optimally for its emissions. Again, such indirect environmental effects are by no means by definition negative. This is related to the simple fact that a road usually runs two ways. It may well be the case that the increase in capacity yields a new spatial equilibrium in which the production of relatively efficient and clean producers has increased and that of inefficient and dirty producers has decreased, as a result of intensified spatial competition. The overall environmental effect may then be positive when summing over increased transport emissions, increased emissions from the clean producers, and decreased emissions from the dirty producers. This argument bears clear parallels with the analysis in Verhoef, Van den Bergh and Button (1997), who consider the effects of environmental transport policies in a spatial equilibrium setting with polluting production sectors; and its exploration too would require the consideration of transport markets in an integrated spatial equilibrium framework.

As a third important type of second-best situation that may complicate CBA in transport, we briefly mention existing distortions in the tax system. When in the application of the rule of half the generalized costs include taxes, it is of course appropriate to consider the changes in the regulator's surplus in addition to changes in consumer (and, when relevant, producer) surpluses: taxes saved or paid constitute no real 
benefit or cost to society, but involve transfers instead. However, to reflect that existing taxes are typically distortionary, a dollar change in total taxes received due to an investment should typically be valued at more than a dollar if the change will in the long run be compensated by changes in taxes elsewhere. This is equivalent to saying that the 'shadow price of public funds', being the social value of an additional dollar of tax revenues, will exceed unity. Of course, a similar correction would have to be made for the valuation of the initial investment costs, when financed directly or indirectly through taxation. Lindsey and Verhoef (2001) discuss this issue in further detail in the context of transport pricing, but the principles discussed there carry over to CBA for transport investments.

We may conclude that the assessment of environmental effects (or costs, when monetized) in transport infrastructure appraisal, although in terms of principles straightforward at first sight, may become more complicated once second-best conditions apply either in the transport mode considered, in the transport system in general, or in the spatial economy that is 'served' by the infrastructure network in which the investment is to be made. This is not so surprising after all, as the principle mimics one of the central conclusions that was emphasized for transport pricing in Lindsey and Verhoef (2001). An implication is that a solid CBA for a transport investment would ideally require analyses with a transport network model (multi-modal when spill-overs between modes are important, and dynamic when the investment considered seeks to reduce peak congestion), and with a multi-sectoral spatial general equilibrium model when market imperfections in the sectors served by the infrastructure are likely to be important.

\subsection{Discounting}

One aspect of CBA that continues to attract much attention involves the choice of a discount rate, needed to bring costs and benefits arising at different moments during the project's life time on an equal footing. The choice of a discount rate may strongly affect the desirability and ranking of different projects considered, so it is a potentially decisive choice that deserves careful consideration. The selection of an appropriate social rate of discounting is not straightforward, if anything because capital markets are not perfect and no single stable interest rate applies throughout the economy and over time (Small, 1999).

The reviews of cost-benefit analysis mentioned earlier discuss various issues pertaining to the selection of a social discount rate. One particular issue that we would like to address here concerns the discounting of the (distant) future in relation to environmental impacts. Various justifications have been given why future environmental degradation should be discounted at a low or even zero discount rate. Most arguments involve intergenerational equity, and a desire to limit adverse environmental impacts of current choices on future generations (Horowitz, 1996). Indeed, future environmental disasters, causing huge social costs, may become practically insignificant in CBA when discounted at market based interest rates (a $1 \$$ loss in 100 years' time is currently worth only $\$ 1 /(1.05)^{100}=0.7$ cents when discounted at a $5 \%$ rate - and 0.006 cents when incurred in 200 years from now). This implication of discounting of course naturally causes unease if it is considered important to protect the environment in the interest of future generations.

Sympathetic to the purpose of protecting future generations' interests as it may be, it should be realized that the use of different discount rates may easily introduce inconsistencies in a CBA or policies in general. Horowitz (1996) for instance presents an example where policies under diverging discount rates will become time-inconsistent: future regulators will not want to follow the current regulator's plans. He suggests to reflect environmental concerns for future generations by adjusting future prices, rather than discount rates, to avoid such inconsistencies. 
Another potential source of inconsistency is that when a project leads to both future benefits and future (environmental) costs, the maximization of net present value under diverging discount rates may lead to choices that can be Pareto-improved upon: i.e., welfare at each moment in time can be improved by making a different decision. This can be illustrated using a simple, abstract example, where a infinitelylived current investment induces an endless future stream of time-invariant benefits B and environmental costs $\mathrm{E}$ (both per year). By choosing some irreversible parameter $\mathrm{x}(0 \leq \mathrm{x} \leq 1)$ now, the regulator can reduce $\mathrm{E}$ at the expense of reducing $\mathrm{B}$, according to:

$\mathrm{E}=0.5 \cdot \mathrm{x}^{2}$

$\mathrm{B}=\mathrm{x}-0.5 \cdot \mathrm{x}^{2}$

With welfare defined as $\mathrm{W}=\mathrm{B}-\mathrm{E}$, it is easily found that a choice of $\mathrm{x}=0.5$ would maximize $\mathrm{W}$ in every period (the first-order condition is $\mathrm{dW} / \mathrm{dx}=1-2 \cdot \mathrm{x}=0$ ), leading to an optimal yearly level of $\mathrm{W}$ equal to $0.25(\mathrm{~B}=0.375 ; \mathrm{E}=0.125)$. When, however, $\mathrm{x}$ is chosen so as to maximize the net present value with $\mathrm{B}$ discounted at an interest rate of $4 \%$ and $\mathrm{E}$ at a lower 'environmental' one of $1 \%$, the objective function becomes:

$\mathrm{NPV}(\mathrm{B})-\mathrm{NPV}(\mathrm{E})=\left(\mathrm{x}-0.5 \cdot \mathrm{x}^{2}\right) / 0.04-\left(0.5 \cdot \mathrm{x}^{2}\right) / 0.01=25 \cdot \mathrm{x}-62.5 \cdot \mathrm{x}^{2}$

which has the first-order condition $25-125 \cdot \mathrm{x}=0$. Hence, $\mathrm{x}$ would be set at 0.2 , leading to a yearly level of $\mathrm{W}$ equal to $0.16(\mathrm{~B}=0.18, \mathrm{E}=0.02)$. Clearly, in this examples, future generations would be better off if the current regulator would discount the project's benefits and environmental costs at equal rates (independent of whether it would be the high or the low one). The current example depends crucially on the assumption that the current choice will affect both future environmental costs and future benefits (as will often be the case for transport investments). A lower discount rate for future environmental costs when benefits would only occur in (the) current period(s) would of course not harm, but benefit, future generations. The example, simple as it may be, warns against a too careless adjustment of discount rates for environmental damages to reflect concerns for future generations.

\subsection{Spatial scope of CBA's}

Transport infrastructures may affect the well-being of people living near to it, but of course also of people living further away. Occasional users from different regions or countries may benefit from new or improved roads, and the environmental impacts may vary from emissions with largely local impacts to the emission of greenhouse gases, potentially inflicting costs on regions whose inhabitants are unlikely to ever use that infrastructure. In a similar vein, it is well-known that the impacts on economic welfare may include substantial distributive effects (e.g., when the increase in welfare for people living near the facility occurs jointly with an induced decrease in welfare elsewhere) in addition to the generative effects (the generation of additional 'total' welfare); see for instance Rietveld (1989). As a result, a project's desirability, as well as the ranking of alternatives, may depend on the definition of the 'planning area' and, with that, of the (spatial) set of individuals whose welfare is assumed to matter in the CBA.

The geographical boundaries for a CBA may in some instances be defined by the jurisdiction that commissions the appraisal, and that would finance the prospective project(s). In other cases, official guidelines may exist that for instance stipulate that the appropriate level of spatial aggregation should be the national one, for instance motivated by the desire to avoid wasteful investments by lower level authorities that would merely redistribute - rather than generate - national welfare. From an overall 
efficiency viewpoint, it is rather obvious that everybody would eventually benefit if all CBA's would take a global perspective and hence consider welfare impacts 'world-wide', and - lump-sum - redistributions between and inside jurisdictions were possible. But this is probably a rather theoretical consideration, that may not be viable in the practice of transport policy making. In any case, the spatial demarcation is an important aspect for the design and the interpretation of CBA's. From the environmental perspective, one could expect that for localized externalities, this demarcation may create a bias in favour of projects running close to the planning area's borders (given population densities) - although a countervailing effect may occur if such routings would reduce the number of home residents that would enjoy improved accessibility. Furthermore, to the extent that this occurs, as well as for global environmental externalities, the spatial demarcation may mean that environmental impacts will not get the weight that would be given when global welfare effects were considered.

\subsection{Transport appraisal and environmental sustainability}

Hanley (1999) raises the interesting question of whether the instrument of CBA in project appraisal, when applied consistently, would lead to the achievement of environmental sustainability - a popular concept in environmental policy making ever since the publication of the Brundtland Report (WCED, 1987). The answer appears to depend on the definition of environmental sustainability used. Indeed, already within 5 years after the Brundtland Report's publication, Pezzey (1993) identified numerous possible definitions and interpretations of the politically popular but scientifically ambiguous concept of sustainability. Hanley (1999) observes that CBA typically does not address intertemporal nor intratemporal equity issues, while distributional considerations are often central to the concept of sustainable development. This points to a first potential inconsistency between CBA and the strive for sustainability, although one might object that different welfare weights could be introduced in the summation of costs and benefits to account at least to some extent for this.

As an aside, it is useful to consider the parallel question of whether a consistent use of CBA in project appraisal would eventually lead to an economically optimal infrastructural configuration. Does any sequence of improvements, until a point is reached where no further improvements can be realized, necessarily bring the system to its optimum? Also this question cannot generally be answered in the affirmative. One important reason is that there may be interdependencies between projects - especially, of course, in transport. It may well be the case that a certain project that would not be selected in isolation would become desirable if other investments are also undertaken; or conversely, that a project has been carried out that after some time becomes redundant when infrastructure at other places and/or in other modes is developed further, or when optimal pricing is introduced on the network (or major parts of it). More generally, with substitute transport modes being at least potentially available and when economies of scale, scope and density in transportation are important, it is certainly not inconceivable that multiple locally (in a mathematical sense) optimal infrastructure configurations exist. The one being achieved when consistently following CBA appraisal's may then depend both on the initial situation and on the sequence in which projects are evaluated and implemented. These considerations would warn against taking too narrow a perspective when defining the set of projects and project variants to be considered in designing CBA's.

Returning to the issue of sustainability, Hanley (1999) further observes that if sustainable development were defined as a non-declining stock of natural resources as some people propose (this 
corresponds to the 'strong' definition, as opposed to 'weak' definitions that allow for substitution between stocks), CBA-based public decision making would in general not guarantee sustainability. A CBA framework, in which costs and benefits of different types are added and subtracted, would instead allow trade-offs between a larger use of environmental resources against increased present (or future) benefits. One could argue that also this apparent inconsistency need not be fundamental, as CBA's can be imagined in which the use of some environmental resources above some threshold levels (possibly zero) is valued at an infinite shadow price. However, this strategy, in turn, may be problematic if the CBA concerns only one relatively small part of the economy, while the threshold concerns the economy-wide use of resources. It would leave unanswered the question of what the threshold should be when considered at the level of an individual project, and it would create complicated interdependencies between CBA's in different areas of the economy, and between CBA's and the (current and future) use of environmental resources in other economic sectors in general. If the resource considered is renewable, one option would be to require that a 'shadow project', that compensates for the use of the resource in the original project, is actually undertaken and is included in the CBA. But environmental concerns often involve non-renewable resources, or unique environmental goods that cannot be replicated exactly. Shadow projects may thus not always provide a fully satisfactory solution to this dilemma.

It is thus clear that CBA's focus on aggregate social surplus rather than on the distribution of costs and benefits, its typical application to individual projects in individual economic sectors, and its related typical application of constant shadow prices for environmental effects, may often be at odds with operational definitions of sustainable development. However, it is worth emphasizing in this context that it has been questioned in the literature whether concepts like 'sustainable transport' can be defined in a meaningful way in the first place, even if 'sustainable development' would be defined unambiguously (e.g., Verhoef, Van den Bergh and Button, 1997). The main concern is that the definition of sustainability of a sub-system with relatively strong interactions with other sub-systems (such as one economic sector - e.g., transport - among many, or one region in a larger spatial system) appears meaningless if such interactions are not taken into account explicitly. This consideration becomes particularly relevant due to the focus of sustainability (and CBA) on long run impacts. To give a simplistic but illustrative example: a complete ban on transport may make it look sustainable from a partial perspective (there would be zero emissions from transport), but the induced additional emissions due to less efficient production following spatial despecialization may make this solution less environmentally sustainable than a configuration with transport. As the same type of concern would apply to an even larger extent to individual investment projects within a sector, one could argue that the observed tension between CBA and the objective of sustainable development need not always point to shortcomings in CBA per se, but may also merely reflect the inherent difficulty (or impossibility) of operationalizing all aspects of sustainable development at the disaggregated level of individual projects. When facing the choice between different projects or variants, this would therefore not necessarily create a systematic bias against CBA when compared to alternative project appraisal techniques.

Two final issues deserve brief consideration. First, as mentioned, it is customary to apply constant shadow prices for environmental effects induced by the projects considered in CBA's, which is often motivated by the small size relative to total emissions in an economy (or in the sector). However, when damage from pollution would depend not only additively on that from different pollutants, but instead the mix of pollutants is also of importance, this simplifying assumption may have to be relaxed. For instance, 
ozone is formed from the interaction of $\mathrm{NO}_{\mathrm{x}}$ and VOC's (Delucchi, 2000). The same holds when the environmental effects considered become damaging only when exceeding some critical level (a classic example being the reversal of ocean streams when global warming exceeds a certain - unknown - level). For reasons comparable to those discussed above, especially when the associated emissions are not solely due to the project(s) considered, this type of 'environmental complexity' (the term used by Hanley, 1999) may lead to complicated interdependencies between CBA's in different sectors, and between CBA's and emissions from other sectors, if these issues are to be given serious treatment in appraisal. But also within a CBA for a given project, these complexities may imply that constant environmental shadow prices are not appropriate. This need not disqualify $\mathrm{CBA}$ as an appraisal technique as such, but may make its execution significantly more complicated.

Second, the policy focus on 'sustainable development' has made future environmental impacts more central in the environmental discourse. Apart from difficulties surrounding discounting (see above), this also makes uncertainty more central in the analysis. Uncertainty may concern both future spatio-economic developments - introducing for instance demand uncertainty - but also the future costs of current emissions. The debate on the existence and severity of global warming is illustrative. Uncertainty may create specific problems for CBA, especially when no information is available that would allow the calculation of expected costs and benefits. In cases where expected environmental costs can be calculated, the next question would be whether or not environmental risk spreading is possible to a sufficient degree so that one could set the social risk premium equal to zero - as suggested by the so-called Arrow-Lind theorem - or whether a positive risk premium would be appropriate. The information required to calculate expected costs will in general be harder to obtain if non-linearities and discontinuities characterize the behaviour of the ecological system (Hanley, 1999). In practice, CBA's may partially account for this by deploying scenario and sensitivity analyses, and environmental policy may be based on precautionary principles that on the one hand may prevent huge irreversible future environmental costs, but on the other hand may lead to considerable current costs or forgone benefits. Regrettably, under this type of uncertainty, by definition no 'optimal degree of precaution' can be established. It is evident that the existence of uncertainty - admittedly unavoidable - may substantially reduce the transparency of CBA's.

\section{The valuation of environmental effects from transport}

Transport investment projects may have many environmental effects, both at the local and global level. The challenge for appraisal has been to find ways of bringing all of these within one framework in a way that allows trade-offs between different types of environmental effects, and between environmental effects and other types of effects. In the following, we first discuss briefly the local, regional and global environmental effects important when evaluating transport investments. The section proceeds with a brief discussion of valuation techniques, and concludes with some recent estimates of environmental costs of transport.

\subsection{Environmental effects of transport}

Various categories of environmental effects from transport and transport infrastructure are usually distinguished. The below listing draws heavily on ECMT (1998).

Transport noise and vibration are, unlike most forms of air pollution, specific in space and especially in time. That is, noise causes nuisance only at the time and place it is emitted, although the effects may be longer-lasted. Transport is a major source of noise annoyance in most societies, partly due to 
its concentration in denser areas. Vibration, particularly by heavy vehicles on uneven surfaces, may in addition cause damage to transport infrastructure, buildings, underground pipes and drains, and so on.

Transport emissions include various types of pollution of (local, regional and global) air quality, for some of which transport is one of the major contributors. While in some respects the environmental damage done by transport is increasing, also reductions have been achieved. Carbon mono- and dioxide, nitrogen oxide, sulphur dioxide, volatile organic compounds and particulate matters are examples of emissions that are measured in this context. Particulates are generally identified as the most significant air pollutant in terms of induced health cost (e.g. Mackie and Nellthorp, 2001; Delucchi, 2000). Its damage costs are much higher per unit mass of pollutant emitted in urban areas, due to the higher density of recipients. The two best known examples of global air pollution are the greenhouse effect, to which transport is a major contributor through emissions of carbon dioxide and other greenhouse gases, and ozone layer depletion, to which transport contributes relatively little (ECMT, 1998).

Visual intrusion may result from the presence of infrastructure and from reduced visibility due to air pollution. It is very difficult to quantify these effects, let alone to value them. Values can be expected to vary strongly between different projects. A new road in a formerly unspoilt area is likely to be viewed differently from one directly parallel to an existing road.

Comparable measurement problems will hinder the valuation of severance of human and natural communities. Also here, difficulties in quantification, however, need not imply unimportance in appraisal. The effects may range from mild hindrance such as waiting times for crossings, to the complete separation of formerly integrated human communities or ecosystems.

Waste disposal is often ignored in appraisal studies. However, the disposal of used oil, coolant and hydraulic fluid, used tyres and batteries, and scrapped vehicles may cause serious damage to the environment. For the latter category, the damage may occur either in the home country, or abroad if international second-hand markets or ecological dumping are important. Also infrastructure construction may results in large quantities of waste, in particular spoil from earthworks.

Water pollution may for instance result from leaks in underground storage tanks or from fuel spilling at gas stations; or from salt, chemicals, or lost oil or other fluids on or near the road that will eventually pollute ground water. This has direct environmental impacts, and may in addition impose costs on local authorities responsible for water quality control.

\subsection{The valuation of environmental externalities}

The consideration of the above types of environmental effects in a CBA requires the identification of the economic value of environmental goods. The difficulty with this is of course that environmental goods are normally not traded, and hence no market price can be observed that would reflect or approximate marginal costs or benefits. Different valuation methods have been developed in the environmental economics literature that aim to identify the shadow prices for these goods. These valuation methods may be directed to one or more of the various types of 'environmental values' that can be distinguished. One possible classification of environmental values, illustrative in that it includes the most often mentioned types, is provided in Table 2 below (based loosely on the discussion in Perman et al., 1999). 


\begin{tabular}{|c|c|c|c|c|c|c|c|c|}
\hline \multicolumn{5}{|c|}{$\begin{array}{l}\text { Use value } \\
\text { (related to the 'use' of the good as a consumption good or production factor - note } \\
\text { that 'consumption' need not always deplete the good: enjoying a scenic view is } \\
\text { also a form of consumption ) }\end{array}$} & \multicolumn{4}{|c|}{$\begin{array}{l}\text { Non-use value } \\
\text { (not related to the 'use' of the good as a consumption } \\
\text { good or production factor) }\end{array}$} \\
\hline \multicolumn{2}{|c|}{$\begin{array}{c}\text { Direct use value } \\
\text { (the use of the good itself) }\end{array}$} & \multicolumn{2}{|c|}{$\begin{array}{l}\text { Indirect use value } \\
\text { (the existence of the good } \\
\text { improves the quantity or quality } \\
\text { of other consumption goods or } \\
\text { production factors }-e . g \text {. fresh } \\
\text { air) }\end{array}$} & \multirow[t]{2}{*}{$\begin{array}{r}\text { Option } \\
\text { (related to } \\
\text { future us } \\
\text { goo }\end{array}$} & $\begin{array}{l}\text { alue } \\
\text { ossible } \\
\text { of the }\end{array}$ & \multirow[t]{2}{*}{$\begin{array}{l}\text { Quasi-option value } \\
\text { (related to possible } \\
\text { future information } \\
\text { on the importance of } \\
\text { the good) }\end{array}$} & \multicolumn{2}{|c|}{ Existence value } \\
\hline $\begin{array}{l}\text { As a } \\
\text { consumption } \\
\text { good }\end{array}$ & $\begin{array}{l}\text { As a } \\
\text { production } \\
\text { factor }\end{array}$ & $\begin{array}{l}\text { Affecting } \\
\text { consumption } \\
\text { goods }\end{array}$ & $\begin{array}{l}\text { Affecting } \\
\text { production } \\
\text { factors }\end{array}$ & & & & $\begin{array}{l}\text { Philan- } \\
\text { thropic } \\
\text { value } \\
\text { (for } \\
\text { contem- } \\
\text { poraries) }\end{array}$ & $\begin{array}{l}\text { Bequest } \\
\text { value } \\
\text { (for } \\
\text { future } \\
\text { genera- } \\
\text { tions) }\end{array}$ \\
\hline
\end{tabular}

Table 2. A classification of different types of environmental values

Regardless of which type of value is considered, valuation methods aim to estimate the individuals' marginal 'willingness-to-pay' (WTP) (in monetary units) for improvements in the quantity or quality of the environmental good concerned, and are therefore consistent with the general philosophy of CBA, in which relevant welfare effects are expressed in monetary units. Economists have developed a number of procedures which, at least in the case of some externalities, do provide reasonable guidance to the monetized value of these effects, despite the remaining uncertainty and dispersion in values produced (Button, 1993a). In recent years the level of sophistication used in this process has risen considerably. A brief outline of possibilities to derive estimates of the value of environmental effects is set out here. Table 3 gives a concise overview of the valuation methods used for environmental externalities, including noise annoyance.

Valuation approaches

Behavioural

Surrogate markets Hypothetical markets

(Revealed preference) (Stated preference)

- Hedonic techniques

- $\quad$ Travel cost methods

- Household production functions
- Contingent valuation in various forms

- Conjoint analysis
Short-cut approaches

Non-behavioural
- Damage costs (buildings, crops, etc.)

- Costs of illness
- Prevention costs: hypothetical defensive, abatement or repair programmes
- Actual defensive, abatement or repair programmes

Adapted from Verhoef (1996)

Table 3. A classification of different types of environmental values

The left-hand side of Table 3 shows 'genuine' valuation methods, reviewed in greater detail in for instance Perman et al. (1999) and in various contributions in Van den Bergh (1999). Among these, behavioural 
techniques deserve preference from a theoretical perspective, as these techniques assess the receptors' valuation. Mitchell and Carson (1989) observe in this respect that there is little theoretical basis for the use of non-behavioural techniques in welfare economics, since the damage functions are not directly related to the consumers' utility functions. Furthermore, non-behavioural techniques measure 'use values' at best (see Table 2), and cannot infer 'non-use' values. Nevertheless, non-behavioural techniques receive much support in practice, in particular since the figures produced appear 'harder'.

Two main categories of behavioural techniques are distinguished. Revealed preference techniques can be applied when surrogate markets for the environmental good to be valued exist; that is, when consumers' marginal willingness to pay for changes in the effect can be measured by looking at their behaviour on other, related markets. Such other markets may be housing markets and labour markets when hedonic techniques are used to statistically infer the value of, for instance, noise annoyance as an attribute of housing services, or safety as an attribute of jobs. The travel cost method would typically seek to measure the valuation for natural parks by looking at the expenses that visitors make in order to see the park. Household production functions can be used to infer how households, in their 'production of utility', try to defend themselves from the impacts of certain externalities. When the goal is to value non-use values, or when no surrogate markets exist, stated preference techniques can be used to infer consumers' willingness to pay by confronting them with hypothetical markets. Contingent valuation studies try to ask for a willingness to pay directly, possibly by confronting respondents with various bids for a certain good. Conjoint analysis techniques typically confront respondents with two (or more) scenarios in which the quantity or quality of an environmental good and some financial transfer vary, and asks them to indicate the most preferred option.

When time or money is lacking to undertake a genuine valuation study, short-cut approaches as indicated on the right-hand side of Table 3 are sometimes used. These can be criticized on many grounds. Important considerations are that circularity may plague the estimates (e.g., an externality that is considered unimportant by the authority would induce small public defensive outlays, which would subsequently produce a low estimate of the external costs), that defensive outlays may not always be possible (it is hard or impossible to protect oneself from global warming or from the extinction of some species), that defensive outlays by private parties are typically carried out up to the point where marginal benefits equal marginal costs so that external costs remain in existence that are not measured using the method, and that hypothetical 'full defence' programmes may on the one hand consider too large a reduction of the externality, but on the other hand bear no relation to the true external costs if they are not actually carried out.

A technique often looked at as the basis for valuation methods involves the construction of doseresponse relationships (e.g., Friedriech and Biekel, 2002). In fact, this is not a separate valuation method, but rather a means of transforming complex effects into a series of items which can be valued more easily (ECMT, 1998). Dose-response work involves estimating physical or medical relationships linking environmental variables to quantifiable effects. Sometimes, the damage categories will involve marketed goods, such as crop yields, and market prices can be used. Many other categories will still be nonmarketed, in which case the effects must be valued using the previous techniques. The so-called value of a statistical life may play an important role in this phase (e.g. Jones-Lee and Loomes, 2002), in particular when concentrations are translated into mortality impacts.

Valuation of non-marketed goods is not an exact science. Uncertainty is inherent in techniques based on statistical inference, and furthermore it is not possible to control for all relevant variables in a 
diverse population. However, valuation studies do provide an indication of the costs and benefits useful to include in the CBA. To account for these uncertainties, it often happens that lowest and highest estimates are provided, along with a central estimate.

\subsection{Some recent estimates of environmental external costs of transport}

Many estimates of external costs of transport have become available over the past decades (e.g. Quinet, 2002). ECMT (1998), for instance, presents values for European countries, whereas Delucchi (2000) summarizes findings for the US. It would take up too much space to give a detailed account of these and other studies here, but for purely illustrative reasons, Tables 4 and 5 provides some summary results from ECMT (1998) and Delucchi (2000).

\begin{tabular}{lcccccc}
\hline & $\begin{array}{c}\text { Passenger cars } \\
\text { Ecu/1000 v-km }\end{array}$ & $\begin{array}{c}\text { Freight trucks } \\
\text { Ecu/1000 v-km }\end{array}$ & $\begin{array}{c}\text { Passenger cars } \\
\text { Ecu/1000 p-km }\end{array}$ & $\begin{array}{c}\text { Rail passengers } \\
\text { Ecu/1000 p-km }\end{array}$ & $\begin{array}{c}\text { Freight trucks } \\
\text { Ecu/1000 t-km }\end{array}$ & $\begin{array}{c}\text { Rail freight } \\
\text { Ecu/1000 t-km }\end{array}$ \\
\hline Noise & 5 & 23 & 3 & 4 & 8 & 6 \\
Air pollution & 13 & 66 & 7 & 2 & 23 & 1 \\
Climate change & 10 & 28 & 6 & 3 & 10 & 1 \\
\hline
\end{tabular}

Adapted from: ECMT (1998), Tables 10 and 11

Table 4. Illustrative environmental external cost estimates (Europe 1990-1995) from ECMT (1998)

The figures in Table 4 give average estimates over countries, vehicle classes, urban versus non-urban traffic and the time of day. The dispersion of cost components over these dimensions may be significant. For instance, ECMT's air pollution cost estimates are based on unit prices of 5 ECU per $\mathrm{kg} \mathrm{NO}_{\mathrm{x}}$, plus 5 ECU per kg VOC's, plus, in cities alone, 70 ECU per kg particulates emitted (ECMT, 1998; Table 9). As a result, the environmental charges calculated by ECMT (1998; Table 17), when adding pollution, noise and climate change, are $0.015 \mathrm{ECU} / \mathrm{v}-\mathrm{km}$ in rural areas and $0.025 \mathrm{ECU} / \mathrm{v}-\mathrm{km}$ in urban areas (note that these figures are lower than what might be gathered from Table 4 above; see Appendix D in ECMT, 1998, for details on the calculations). Both correspond to around $25 \%$ of the total optimal charges calculated, which include for instance external accident costs, infrastructure costs and congestion. Also the representation in terms of costs per kilometre may be somewhat misleading. That is, the difference in emissions per vehicle mile may be a factor 10 or more, depending on whether one considers a cold or hot engine (ECMT, 1998; Table 62). Likewise, traffic conditions may of course have a great impact on emissions per kilometre.

\begin{tabular}{lcccccc}
\hline & $\begin{array}{c}\text { Low } \\
10^{9} \$\end{array}$ & $\begin{array}{c}\text { High } \\
10^{9} \$\end{array}$ & $\begin{array}{c}\text { Low } \\
\$ / 1000 \mathrm{v}- \\
\mathrm{mile}^{\mathrm{a}}\end{array}$ & $\begin{array}{c}\text { High } \\
\$ / 1000 \mathrm{v}- \\
\mathrm{mile}^{\mathrm{a}}\end{array}$ & $\begin{array}{c}\text { Low } \\
\$ / 1000 \mathrm{v}- \\
\mathrm{km}^{\mathrm{b}}\end{array}$ & $\begin{array}{c}\text { High } \\
\$ / 1000 \mathrm{v}- \\
\mathrm{km}^{\mathrm{b}}\end{array}$ \\
\hline $\begin{array}{l}\text { Air pollution } \\
\quad \text { (of which human health related) }\end{array}$ & 32.4 & 493.1 & 14.9 & 226.9 & 24.0 & 365.2 \\
Water pollution & $(24.3)$ & $(450.0)$ & $(11.2)$ & $(207.1)$ & $(18.0)$ & $(333.3)$ \\
Noise & 0.4 & 1.5 & 0.2 & 0.7 & 0.3 & 1.1 \\
Climate change & 0.5 & 15 & 0.2 & 6.9 & 0.4 & 11.1 \\
Total & 5.0 & 37.0 & 2.3 & 17.0 & 3.7 & 27.4 \\
\hline
\end{tabular}

${ }^{a}$ Calculated using the total VMT figures for 1991 in Delucchi (1997; Table 5.2), summing over all vehicle types

${ }^{\mathrm{b}}$ Using $1 \mathrm{mile}=1.6093 \mathrm{~km}$

Adapted from Delucchi (2000; Table 6) 
Table 5 summarizes some main findings by Delucchi (2000), who reports the total environmental costs of motor vehicle use for the US in 1990-1991 (the first two columns in Table 5 below). The results for instance illustrate that air pollution is the most important component in the external environmental costs of road transport, and that the uncertainty of estimates, as represented by the difference between the low and high estimates, is substantial.

Only because we suspect that some readers may otherwise make the same 'quick-and-dirty' calculations themselves in order to compare the estimates in Tables 4 and 5, we have converted the figures in the latter into per vehicle-km values on a very rough basis (averaged over all vehicle types, including passenger cars and trucks). This suggests that Delucchi's low estimate for air pollution and his high estimate for noise would be of the same order of magnitude as the ECMT figures (note that the ECMT figures are in ECU's, which were later converted into Euro's on a 1 to 1 basis, while Delucchi's are in dollars; and also note that we have not attempted to convert the estimates to the same base year). Such differences may be due to a wide number of causes, including local conditions (e.g. population densities), differences in the 'true' consumers' valuation of external effects, valuation methods used, environmental characteristics of vehicles, and vehicle mixes in average traffic conditions. A detailed comparison is outside the scope of this review.

\section{Conclusion}

Transport investment appraisal can be seen as a tool to rationalise investment decisions. If the project is analysed on behalf of government, then a broad appraisal will be required, considering all relevant economic and social impacts of the scheme. Environmental effects comprise one important category of such impacts. This review considered the inclusion of environmental effects in transport investment appraisal mainly from the perspective of cost-benefit analysis, the most widely adopted appraisal technique.

Although the basic principles of CBA are straightforward, several complications were identified that may play an important role in practical CBA's. These include second-best aspects, difficulties with discounting and with the spatial scope of CBA's, and the relation between CBA and the popular but multifaceted and often ill-defined policy concept of sustainable development.

CBA takes individuals willingness to pay as the starting point for valuation of effects. Values for time, safety and environmental impacts can derived from surrogate or hypothetical markets. Although the environmental effects from transport projects are well-recognized and increasingly well understood, it is not always obvious how these should be valued in order to include them into a CBA. One of the challenges for cost-benefit analysis is then to find ways of bringing all the environmental impacts within the CBAframework in a way that does not impose problems of inconsistency, and which reflects in an appropriate way the much greater uncertainty associated with many environmental impacts.

\section{Acknowledgements}

The authors would like to thank an anonymous referee for corrections and insightful comments on an earlier version of this paper. Any remaining errors, however, are the authors' responsibility alone. Erik Verhoef's research has been supported by a fellowship of the Royal Netherlands Academy of Arts and Sciences. 


\section{References}

Braess, D. (1968) “Über ein Paradoxen des Verkehrsplanung” Unternehmenforschung, 12, 258-268.

Button, K. (1993a) Transport, The Environment and Economic Policy, Edward Elgar, Aldershot.

Button, K. (1993b) Transport Economics (2 ${ }^{\text {nd }}$ Edition), Edward Elgar, Aldershot.

Delucchi, M.A. (2000) "Environmental externalities of motor-vehicle use in the US" Journal of Transport Economics and Policy 34 (2) 135-168.

Delucchi, M.A. (1997) "The annualized social cost of motor-vehicle use in the US based on 1990-1991 data: summary of theory, data, methods and results". In: D.L. Greene, D.W. Jones and M.A. Delucchi (eds.) (1997) The Full Costs and Benefits of Transportation: Contributions to Theory, Method and Measurement Springer-Verlag, Heidelberg, 27-68.

Dupuit, J. (1844) "On the measurement of the utility of public works". In: D. Murphy (1968) Transport Penguin, London.

ECMT (1998) Efficient Transport for Europe, Policies for Internalisation of External Costs European Conference of Ministers of Transport, OECD, Publications Service, Paris.

Friedriech, R. and P. Biekel (2002) Environmental External Costs of Transport, Springer Verlag, Berlin.

Grant-Muller, S.M., P. Mackie, J. Nellthorp and A. Pearman (2001) "Economic appraisal of European transport projects: the state of the art revisited" Transport Reviews 2 (2) 237-261.

Hanley, N. (1999) “Cost-Benefit Analysis of Environmental Policy and Management”. In: J.C.J.M. van den Bergh (ed.) (1999) Handbook of Environmental and Resource Economics Edward Elgar, Aldershot, pp. 824-836.

Horowitz, J.K. "Environmental policy under a non-market discount rate" Ecological Economics 16 73-78.

Janssen, R. and G. Munda (1999) "Multi-criteria methods for quantitative, qualitative and fuzzy evaluation problems". In: J.C.J.M. van den Bergh (ed.) (1999) Handbook of Environmental and Resource Economics Edward Elgar, Aldershot, pp. 837-852.

Jones-Lee, M. and G. Loomes (2002) "Valuation of safety". In: D.A. Hensher and K.J. Button (eds.) (2002) Handbook of Transport and Environment, Handbooks in Transport 4 Elsevier / Pergamon, Amsterdam, forthcoming.

Lindsey, C.R. and E.T. Verhoef (2001) "Traffic congestion and congestion pricing". In: D.A. Hensher and K.J. Button (eds.) (2001) Handbook of Transport Systems and Traffic Control, Handbooks in Transport 3 Elsevier / Pergamon, Amsterdam, pp. 77-105.

Mackie, P. and J. Nellthorp (2001) "Cost-Benefit Analysis in Transport”. In D.A. Hensher and K.J. Button (eds.) (2001) Handbook of Transport Systems and Traffic Control, Handbooks in Transport 3 Elsevier / Pergamon, Amsterdam, pp. 143-174.

McCubbin, D.R. and M.A. Delucchi (1999) "The Health Costs of Motor-Vehicle-Related Air Pollution" Journal of Transport Economics and Policy 33 (3) 253-286.

Mitchell, R.C. and R.T. Carson (1989) Using Surveys to Value Public Goods: The Contingent Valuation Method Resources for the Future, Washington.

Nash, C. A. (1993) "Cost-Benefit Analysis of Transport Projects". In: A. Williams and E. Giardina (eds.) (1993) Efficiency in the Public Sector: The Theory and Practice of Cost-Benefit Analysis Edward Elgar, Aldershot, pp. 83-105. 
Nijkamp, P. and R. Vreeker (2003) "Multicriteria Analysis". In: D.A. Hensher and K.J. Button (eds.) (2003) Handbook of Transport Strategies, Policies and Institutions, Handbooks in Transport 6 Elsevier / Pergamon, Amsterdam, forthcoming.

Parry, I.W.H. and A. Bento (2002) "Estimating the welfare effect of congestion taxes: the critical importance of other distortions within the transport system" Journal of Urban Economics 51 339-365.

Perman, R., Y. Ma, J. McGilvray, and M. Common (1999) Natural Resource \& Environmental Economics (2nd edition) Addison Wesley, Longman Ltd., UK.

Pezzey, J. (1993) "Sustainability: an interdisciplinary guide" Environmental Values 1 321-62.

Prest, A.R., and R. Turvey (1965) The Social Appraisal of Projects - A text in Cost-Benefit Analysis, Macmillan, London.

Quinet, E. (2002) “Evaluation of environmental impacts”. In: D.A. Hensher and K.J. Button (eds.) (2002) Handbook of Transport and Environment, Handbooks in Transport 4 Elsevier / Pergamon, Amsterdam, pp. forthcoming.

Rietveld, P. (1989) "Infrastructure and regional development: a survey of multiregional economic models" Annals of Regional Science 23 255-274.

SACTRA (1999) Transport and the Economy, Department of the Environment, Transport and the Regions, London (http://www.roads.dft.gov.uk/roadnetwork/sactra/report99/).

SAMI (2000) Strategic Assessment for the Interaction of CTP-Instruments, Deliverable 4, Project Funded by the European Commission under the $4^{\text {th }}$ Framework Programme, Brussels.

Small, K.A. (1992) Urban Transportation Economics. Fundamentals of Pure and Applied Economics. Harwood, Chur.

Small, K.A. (1999) "Project Evaluation”. In: J. Gómez-Ibáñez, W.B. Tye and C. Winston (eds.) (1999) Essays in Transportation Economics and Policy Brookings Institution Press, Washington, pp. 137-177.

Van den Bergh, J.C.J.M. (1999) Handbook of Environmental and Resource Economic Edward Elgar, Aldershot.

Varian, H. (1992) Microeconomic Analysis (2 ${ }^{\text {nd }}$ edition) Norton, New York.

Verhoef, E.T. (1996) The Economics of Regulating Road Transport Edward Elgar, Cheltenham.

Verhoef, E.T., J.C.J.M. van den Bergh and K.J. Button (1997) "Transport, spatial economy and the global environment" Environment and Planning 29A 1195-1213.

WCED (World Commission on Environment and Development) (1987) Our Common Future Oxford University Press, Oxford/New York.

Williams, H.C.W.L. and L.A.R. Moore (1990), "Appraisal of highway investments under fixed and variable demand" Journal of Transport Economics and Policy 24 61-81.

Willig, R.D. (1976) “Consumer’s surplus without apology” American Economic Review 66 589-597. 


\section{Endnotes}

${ }^{1}$ A good is said to be a 'public good' when its consumption satisfies two criteria, namely 'non-rivalry' (the consumption by one
actor does not reduce availability for other actors) and non-excludability (it is practically or economically impossible to exclude,
through prices, an actor from consuming the good). A standard example of a public good concerns protection from floods
through dykes. A free market will typically not lead to an efficient supply of public goods. See, among many others, Varian
(1992) for a detailed discussion.
${ }^{2}$ An externality or external effect is said to exist when the behaviour of the one actor directly affects the well-being of another
actor, while there is no market on which the effect is traded. A standard example of an externality concerns air pollution. A free
market will typically not lead to an efficient outcome when external effects exist. See, among many others, Varian (1992) for a
detailed discussion.
${ }^{3}$ Discounting of future costs and benefits is a procedure that aims to account for the fact that future costs and benefits at present
have a lower value than current costs and benefits of the same size. For instance, with a constant market interest rate of $5 \%$,
receiving $\$ 100$ now and putting it on a bank account is equivalent to receiving $1.05 . \$ 100=\$ 105$ in one year's time, or
$1.05 \cdot 1.05 \cdot \$ 100=\$ 110.25$ in two years' time. Similarly, the obligation to pay $\$ 100$ in one year's time is equivalent to the
obligation to pay $\$ 100 / 1.05=\$ 95.24$ immediately: putting that amount of money on a bank account suffices to pay the $\$ 100$ one
year later. Time discounting reflects these principles, and the net present value of a project that involves costs $C_{t}$ and benefits $B_{t}$
in years $t$, with a lifetime of $T$ years and a constant interest rate of $r$, can accordingly be calculated as: $N P V=\sum_{t=0}^{T} \frac{B_{t}-C_{t}}{(1+r)^{t}}$

(see also Mackie and Nellthorp, 2001). 